\title{
Differential in vitro activity of the DNA topoisomerase inhibitor idarubicin against Trypanosoma rangeli and Trypanosoma cruzi
}

\author{
Momodou Jobe, Charles Anwuzia-Iwegbu, Ama Banful, Emma Bosier, Mubeen Iqbal, \\ Kelly Jones, Suzanne J Lecutier, Kasimir Lepper, Matt Redmond, Andrew Ross-Parker, \\ Emily Ward, Paul Wernham, Eleanor M Whidden, Kevin M Tyler, Dietmar Steverding/ ${ }^{+}$
}

BioMedical Research Centre, Norwich Medical School, University of East Anglia, Norwich, UK

In this study the effect of eight DNA topoisomerase inhibitors on the growth Trypanosoma rangeli epimastigotes in cell culture was investigated. Among the eight compounds tested, idarubicin was the only compound that displayed promising trypanocidal activity with a half-maximal growth inhibition $\left(G I_{50}\right)$ value in the sub-micromolar range. Fluorescence-activated cell sorting analysis showed a reduction in DNA content in T. rangeli epimastigotes when treated with idarubicin. In contrast to T. rangeli, against Trypanosoma cruzi epimastigotes idarubicin was much less effective exhibiting a $\mathrm{GI}_{50}$ value in the mid-micromolar range. This result indicates that idarubicin displays differential toxic effects in $\mathrm{T}$. rangeli and $\mathrm{T}$. cruzi. Compared with African trypanosomes, it seems that American trypanosomes are generally less susceptible to DNA topoisomerase inhibitors.

Key words: Trypanosoma rangeli - Trypanosoma cruzi - Chagas disease DNA topoisomerase inhibitors - drug screening - chemotherapy

\begin{abstract}
Chagas disease is caused by the protozoan parasite Trypanosoma cruzi and occurs mainly in Central and South America. Approximately 10 million people are infected with the parasite and in 2008 the disease killed more than 10,000 individuals (WHO 2010). Only two drugs, benznidazole and nifurtimox, are available for treatment of Chagas disease (Urbina \& Docampo 2003, WHO 2010). Both drugs were developed 40 years ago and are only effective in the acute phase of the disease (WHO 2010). In addition, both remedies have significant side effects, ranging from nausea to life-threatening complications (Urbina \& Docampo 2003). Thus, the development of new drugs for treatment of Chagas disease is urgently required.

One strategy to identify new chemotherapies for treatment of Chagas disease is the screening of existing drugs for antichagasic activity. In this context, DNA topoisomerase and proteasome inhibitors approved for cancer chemotherapy have been shown to display promising trypanocidal activities (Deterding et al. 2005, Steverding \& Wang 2009). Moreover, previous studies have shown that bacterial topoisomerase inhibitors block proliferation and differentiation of T. cruzi (Pate et al. 1986, Gonzales-Perdomo et al. 1990). The aim of this study was to investigate whether commercially available eukaryotic DNA topoisomerase inhibitors show anti-trypanosomal activities against American trypanosomes.
\end{abstract}

Financial support: Wellcome Trust (081059/Z/06/Z), The European Union Seventh Framework Program (223034)

+ Corresponding author: dsteverding@hotmail.com

Received 14 September 2011

Accepted 6 August 2012
DNA topoisomerases are essential enzymes that catalyse topological changes in DNA and therefore play key roles in replication, transcription, recombination and chromosome condensation (Corbett et al. 2004, Bates \& Maxwell 2005). Two types of topoisomerase have been characterised: type I topoisomerases introduce transient single-strand breaks in DNA, whereas type II topoisomerases produce transient double-strand breaks (Berger et al. 1996, Stewart et al. 1998). Topoisomerases are critical to completion of successful cell cycles and, therefore, have been developed as drug targets both for antimicrobial and anticancer chemotherapy. Most anticancer topoisomerase inhibitors (anthracyclins, camptothecins, mitoxantrone and etoposide) poison topoisomerases by inhibiting the DNA religation activity of the enzymes (Pommier et al. 2010). In addition, if anti-cancer drugs targeting topoisomerases prove effective in killing T. cru$z i$, a more rapid application for treatment of Chagas disease with less extensive clinical trials might be possible as their in vivo toxicities are already well established.

Trypanosoma rangeli is a New World trypanosome species which is non-pathogenic for mammals and is frequently found to be infecting humans (Guhl \& Vallejo 2003). Its geographical distribution overlaps with that of T. cruzi and it shares the same vertebrate hosts and insect vectors. $T$. rangeli is closely related to $T$. cruzi with similar morphology and antigenicity which can complicate diagnosis. Phylogenetic analyses indicate that although each of these sibling species have discrete monophyletic origins they share a common origin and group closely together to the exclusion of other trypanosomes (Stevens et al. 1999, Ortiz et al. 2009). Moreover, both species show considerable genetic heterogeneity. T. cruzi diversity is currently encompassed in six disease typing units (DTUs) I-VI (Zingales et al. 2009) where DTU I (TcI) and DTU II (TcII) are most divergent from one another 
(Westenberger et al. 2005). In addition, TcI is the most abundant and widely dispersed of all the T. cruzi DTUs in the Americas while TcII is predominantly found in southern and central regions of South America (Zingales et al. 2012). Moreover, TcII associated with megasyndromes, as well as cardiac manifestations, has been isolated mainly from domestic transmission (Zingales et al. 2012). For these reasons, DNA topoisomerase inhibitors were initially screened with $T$. rangeli and effective compounds were then tested for their activity against two $T$. cruzi strains, one from DTU I (Sylvio X10) and the other from DTU II (Esmeraldo).

The trypanocidal activity of eight DNA topoisomerase inhibitors used as anticancer drugs was evaluated in a growth assay with epimastigotes of $T$. rangeli (Choachi strain) (Grisard et al. 1999). In brief, cells were seeded in 24-well plates in a final volume of $1 \mathrm{~mL}$ liver infusion tryptose medium plus $15 \%$ heat-inactivated foetal calf serum (Grisard et al. 1999) containing various concentrations of DNA topoisomerase inhibitors $\left(10^{-4}\right.$ $10^{-9} \mathrm{M}$ ) dissolved in $100 \%$ dimethyl sulfoxide (DMSO). The controls contained DMSO alone. In all experiments, the final DMSO concentration was $1 \%$. The seeding densities were $0.6-1 \times 10^{6}$ parasites per $\mathrm{mL}$. After $24 \mathrm{~h}$ incubation at $27^{\circ} \mathrm{C}$, live cells were counted using a haemocytometer. The $50 \%$ growth inhibition value $\left(\mathrm{GI}_{50}\right)$, i.e. the inhibitor concentration necessary to reduce the growth rate of the cells to half of that of controls was determined by linear interpolation using the following equation ( $\mathrm{Hu}-$ ber \& Koella 1993):

$$
\log \left(\mathrm{GI}_{50}\right)=\log \left(x_{1}\right)+\frac{\left(y_{1}-y_{0} / 2\right)}{\left(y_{1}-\mathrm{y}_{2}\right)} \times\left[\log \left(x_{2}\right)-\log \left(x_{1}\right)\right]
$$

where $x_{1}$ is the drug concentration at where the cell density $y_{1}$ is more than half of the density $y_{0}$ found in the control and $x_{2}$ is the drug concentration at where the cell density $y_{2}$ is less than half of the control. The minimum inhibitory concentration (MIC), i.e. the lowest concentration of the inhibitor at which all cells were killed, was determined microscopically.

With the exception of the anthracyclines aclarubicin and idarubicin, all other DNA topoisomerase inhibitors displayed no activity against $T$. rangeli epimastigotes (Table I). Only idarubicin exhibited promising trypanocidal activity (Fig. 1) with $\mathrm{GI}_{50}$ values in the sub-micromolar range (Table I). Compared with ketoconazole, a wellknown antifungal and antiparasitic agent, idarubicin was 50 times more effective against $T$. rangeli (Table I). That most of the DNA topoisomerase inhibitors exhibited little or no activity was unexpected as this class of compounds was previously shown to be very effective against Trypanosoma brucei bloodstream forms with $\mathrm{GI}_{50}$ values ranging from 3-20 $\mu \mathrm{M}$ (Deterding et al. 2005). In addition, the anthracenedione mitoxantrone was recently reported to induce an inhibitory effect on cellular proliferation of $T$. cruzi epimastigotes with a $\mathrm{GI}_{50}$ value in the low micromolar range (Zuma et al. 2011). That the two camptothecin analogues, topotecan and irinotecan, showed no activity against $T$. rangeli, may be due to the fact that both inhibitors are hydrophilic compounds (Rothenberg 1997). However, to prove this hypothesis, additional experiments are needed to be performed. Likewise, both drugs showed only weak activity against $T$. brucei bloodstream forms (Deterding et al. 2005). However, the parent compound of topotecan and irinotecan, camptothecin, was reported to significantly inhibit the growth of $T$. brucei bloodstream forms and $T$. cruzi epimastigotes with $\mathrm{GI}_{50}$ values of around 0.4 and $2.1 \mu \mathrm{M}$, respectively (Bodley \& Shapiro 1995, Deterding et al. 2005, Zuma et al. 2011).

As G2/M arrest is a well-documented effect of topoisomerase II inhibitors (Larsen et al. 2003) we studied the impact of idarubicin on cell cycle distribution in $T$. rangeli. Epimastigote forms of T. rangeli were incubated

TABLE I

Minimum inhibitory concentration (MIC) and growth inhibition values $\left(\mathrm{GI}_{50}\right)$ of DNA topoisomerase inhibitors for Trypanosoma rangeli

\begin{tabular}{|c|c|c|c|c|}
\hline Compound & Target & $\mathrm{n}$ & $\begin{array}{l}\text { MIC } \\
(\mu \mathrm{M})\end{array}$ & $\begin{array}{c}\mathrm{GI}_{50} \\
(\mu \mathrm{M})\end{array}$ \\
\hline \multicolumn{5}{|l|}{ Anthracyclines } \\
\hline Aclarubicin & Topo I, II, proteasome & 3 & 100 & $20.9 \pm 8.8$ \\
\hline Doxorubicin & Topo II & 2 & $>100$ & $>100$ \\
\hline Epirubicin & Topo II & 2 & $>100$ & $>100$ \\
\hline Idarubicin & Topo II & 3 & 100 & $0.49 \pm 0.27$ \\
\hline \multicolumn{5}{|l|}{ Camptothecins } \\
\hline Irinotecan & Topo I & 3 & $>100$ & $>100$ \\
\hline Topotecan & Topo I & 3 & $>100$ & $>100$ \\
\hline \multicolumn{5}{|l|}{ Miscellaneous } \\
\hline Etoposide & Topo II & 3 & $>100$ & $>100$ \\
\hline Mitoxantrone & Topo II & 2 & $>100$ & $>100$ \\
\hline \multicolumn{5}{|c|}{ Antichagasic drug } \\
\hline Ketoconazole & Ergosterol & 7 & $>100$ & $25.7 \pm 12.9$ \\
\hline
\end{tabular}


with DMSO (control) or $10 \mu \mathrm{M}$ idarubicin, a concentration 10-fold lower than the MIC value (Table I). After $18 \mathrm{~h}$ incubation, the cells were washed with $\mathrm{PBS} / 1 \%$ glucose and fixed in ice-cold methanol (Ormerod 2000). Then, cells were stained with $50 \mu \mathrm{g} / \mathrm{mL}$ propidium iodide in water and analysed with a BD Accuri C6 flow cytometer. Idarubicin failed to arrest $T$. rangeli in $\mathrm{G} 2 / \mathrm{M}$ as is evident from the disappearance of the G2/M cell population (Fig. 2). Instead, idarubicin treatment resulted in a reduction of DNA content in many cells (Fig. 1) (sub G1 cell population). A similar result was also obtained with

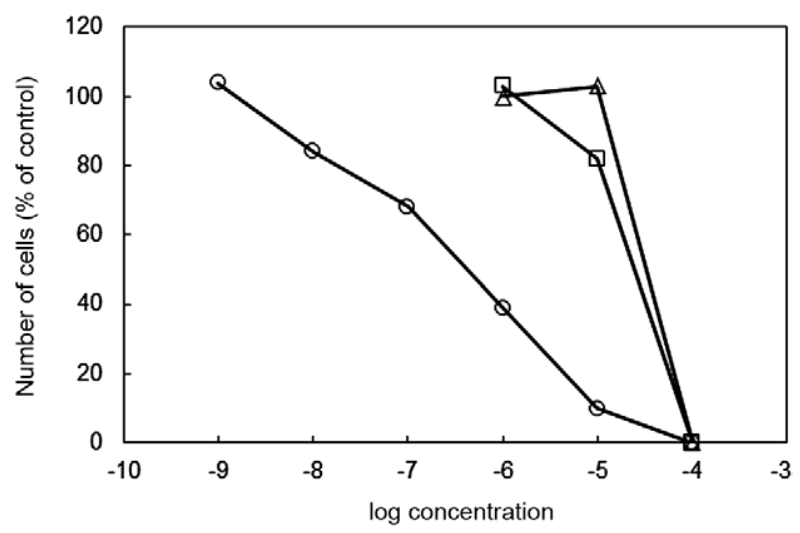

Fig. 1: effect of idarubicin on the growth of Trypanosoma rangeli and Trypanosoma cruzi. Epimastigotes of T. rangeli (circles) and T. cruzi Sylvio X10 (squares) and Esmeraldo (triangles) strains were incubated with varying concentrations of idarubicin. After $24 \mathrm{~h}$ of culture, motile cells were counted using a haemocytometer. Mean values of three experiments are shown.

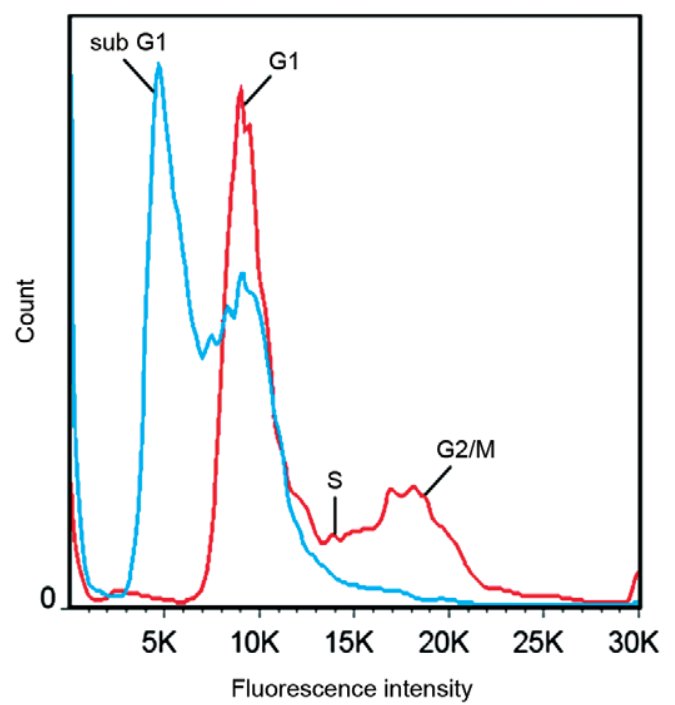

Fig. 2: cell cycle distribution of Trypanosoma rangeli exposed to idarubicin. Epimastigotes of $T$. rangeli were treated with $10 \mu \mathrm{M}$ idarubicin (blue line) or vehicle (dimethyl sulfoxide, red line) and stained with propidium iodide. DNA content was analysed by flow cytometry.
$1 \mu \mathrm{M}$ idarubicin although DNA reduction was not so pronounced as with $10 \mu \mathrm{M}$ idarubicin (data not shown). No difference in cell cycle distribution compared to control cells was seen with $0.1 \mu \mathrm{M}$ idarubicin (data not shown). This is reminiscent of the observation for doxazolidinetreated mammalian cells where apoptosis is induced and DNA is degraded (Kalet et al. 2007). These data suggest that idarubicin's mechanism of cytotoxicity is probably topoisomerase II independent.

Next, the effect of idarubicin on epimastigotes of two T. cruzi strains, Sylvio X10 and Esmeraldo, was tested using the same growth assay as described for $T$. rangeli. The seeding densities ranged between $0.9-1.3 \times 10^{6}$ parasites per mL. Both T. cruzi strains were less susceptible to idarubicin than T. rangeli (Fig. 1) with $\mathrm{GI}_{50}$ values in the midmicromolar range (Table II). Based on the $\mathrm{GI}_{50}$ values, the Sylvio X10 strain was slightly more resistant (1.5 times) towards idarubicin than the Esmeraldo strain $(\mathrm{p}=0.052)$.

Our results when compared with those published for the African trypanosomes (Deterding et al. 2005) indicate that American trypanosomes are less sensitive to DNA topoisomerases inhibitors. That DNA topoisomerase inhibitors affect $T$. rangeli and $T$. cruzi differently to $T$. brucei has important implication for the potential use of this class of drugs as broad-spectrum trypanocides. The differences in susceptibility towards DNA topoisomerase inhibitors between American and African trypanosomes may have a variety of causes. First, there may be a difference in the uptake of the drugs by the different trypanosome species. All DNA topoisomerase inhibitor tested in this study are lipophilic compounds and, therefore, should be able to enter cells by passive diffusion. As the diffusion rate is a function of temperature, the bloodstream forms of $T$. brucei cultivated at $37^{\circ} \mathrm{C}$ could be expected to take up the drugs more quickly than epimastigotes of T. rangeli and $T$. cruzi grown at $27^{\circ} \mathrm{C}$. Second, the different life-cycle stages of trypanosomes (mammalian vs. insect) may have different sensitivities towards DNA topoisomerase inhibitors. Third, inhibition of topoisomerases is predicted to affect bloodstream forms of T. brucei to a greater extent as they have a faster proliferation rate compared to epimastigotes of T. rangeli and T. cruzi.

Since the molecular inhibition mechanism of idarubicin is not different from that of the other anthracyclines tested in this study (Plumbridge \& Brown 1978), why is idarubicin the only compound displaying trypanocidal activity against $T$. rangeli? The answer to this question may

\section{TABLE II}

Minimum inhibitory concentration (MIC) and growth inhibition values $\left(\mathrm{GI}_{50}\right)$ of idarubicin for Trypanosoma cruzi

\begin{tabular}{lccc}
\hline Strain & $\mathrm{n}$ & $\begin{array}{c}\mathrm{MIC} \\
(\mu \mathrm{M})\end{array}$ & $\begin{array}{c}\mathrm{GI}_{50} \\
(\mu \mathrm{M})\end{array}$ \\
\hline Sylvio X10 (DTU I) & 3 & 100 & $38.5 \pm 6.9$ \\
Esmeraldo (DTU II) & 3 & 100 & $24.6 \pm 2.4$ \\
\hline
\end{tabular}

DTU: disease typing unit. 
lie in the structure of the molecules. Idarubicin differs from doxorubicin and epirubicin by the deletion of a methoxy group at the position $\mathrm{C}-4$ of the basic anthracycline ring scaffold. This modification results in a higher lipophilic coefficient with the effect that idarubicin is taken up more rapidly and induces more DNA single strand breaks (Supino et al. 1977, Schwartz \& Kanter 1981). The trypanocidal activity of aclarubicin (which has a hydroxyl group at position C-4 and therefore should be inactive) can be explained by the fact that it also inhibits DNA topoisomerase I (Bridewell et al. 1997) and the proteasome (FigueiredoPereira et al. 1996). Mitoxantrone has hydroxyl groups at position C-1 and C-4 of the anthracenedione ring scaffold which would make it less lipophilic explaining its inactivity. These structure-activity relationships suggest that in order to exhibit trypanocidal activity DNA topoisomerase inhibitors should be highly lipophilic.

Although T. rangeli and T. cruzi are considered sibling species, for some drugs such as nifurimox it appears that they have similar susceptibility (Marinkelle 1982). However, this is clearly not always the case (Avila et al. 1981). Here we have demonstrated a significant difference in drug susceptibility to idarubicin, a drug which displayed substantial trypanocidal activity against $T$. rangeli, but not against $T$. cruzi. Bioinformatics analysis does suggest some significant differences in the topoisomerase repertoire between $T$. rangeli and T. cruzi (EC Grisard, unpublished observations) and this heterogeneity may well be the reason for the difference in susceptibility that we observe. These findings reinforce the view that although the use of T. rangeli as a "laboratory safe" surrogate for T. cruzi in drug screening and pre-screening is appealing and may well be useful, where it is used the results should be interpreted with care. In addition, our results also indicate that the use of insect forms has drawbacks for screening potential drugs for Chagas disease because these life cycle stages can have different sensitivities than mammalian forms to antichagasic agents.

\section{ACKNOWLEDGEMENTS}

To Edmundo Grisard and Claire Butler, for provision and instruction in the growth of T. rangeli and T. cruzi, and to Darren Sexton and Andrew Goldson, for their help with flow cytometry analyses and preparing of the histogram.

\section{REFERENCES}

Avila JL, Avila A, de Casanova MA 1981. Differential metabolism of allopurinol and derivatives in Trypanosoma rangeli and $T$. cruzi culture forms. Mol Biochem Parasitol 4: 265-272.

Bates AD, Maxwell A 2005. DNA topology, Oxford University Press, Oxford, $220 \mathrm{pp}$.

Berger JM, Gamblin SJ, Harrison SC, Wang JC 1996. Structure and mechanism of DNA topoisomerase II. Nature 379: 225-232.

Bodley AL, Shapiro TA 1995. Molecular and cytotoxic effects of camptothecin, a topoisomerase I inhibitor, on trypanosomes and Leishmania. Proc Natl Acad Sci USA 92: 3726-3730.

Bridewell DJ, Finlay GJ, Baguley BC 1997. Differential action of aclarubicin and doxorubicin: the role of topoisomerase I. Oncol Res 9: 535-542.

Corbett KD, Berger JM 2004. Structure, molecular mechanisms and evolutionary relationships in DNA topoisomerases. Аппи Rev Biophys Biomol Struct 33: 95-118.
Deterding A, Dungey FA, Thompson K-A, Steverding D 2005. Antitrypanosomal activities of DNA topoisomerase inhibitors. Acta Trop 93: 311-316.

Figueiredo-Pereira ME, Chen WE, Li J, Johdo O 1996. The antitumor drug aclacinomycin A, which inhibits the degradation of ubiquitinated proteins, shows selectivity for the chymotrypsin-like activity of the bovine pituitary $20 \mathrm{~S}$ proteasome. J Biol Chem 271: 16455-16459.

Gonzales-Perdomo M, de Castro SL, Meirelles MN, Goldenberg S 1990. Trypanosoma cruzi proliferation and differentiation are blocked by topoisomerase II inhibitors. Antimicrob Agents Chemother 34: 1707-1714.

Grisard EC, Campbell DA, Romanha AJ 1999. Mini-exon gene sequence polymorphism among Trypanosoma rangeli strains isolated from distinct geographical regions. Parasitology 118: 375-382.

Guhl F, Vallejo GA 2003. Trypanosoma (Herpetosoma) rangeli Tejera, 1920 - an updated review. Mem Inst Oswaldo Cruz 98: 435-442.

Huber W, Koella JC 1993. A comparison of three methods of estimating $\mathrm{EC}_{50}$ in studies of drug resistance of malaria parasites. Acta Trop 55: 257-261.

Kalet BT, McBryde MB, Espinosa JM, Koch TH 2007. Doxazolidine induction of apoptosis by a topoisomerase II independent mechanism. J Med Chem 50: 4493-4500.

Larsen AK, Escargueil AE, Skladanowski A 2003. From DNA damage to G2 arrest: the many roles of topoisomerase II. Prog Cell Cycle Res 5: 295-300.

Marinkelle CJ 1982. The effect of Lampit on Trypanosoma rangeli in experimentally infected mice. Tropenmed Parasitol 33: 151-152.

Ormerod MG 2000. Flow cytometry: a practical approach, Oxford University Press, Oxford, $276 \mathrm{pp}$.

Ortiz PA, Maia da Silva F, Cortez AP, Lima L, Campaner M, Pral EM, Alfieri SC, Teixeira MM 2009. Genes of cathepsin L-like proteases in Trypanosoma rangeli isolates: markers for diagnosis, genotyping and phylogenetic relationships. Acta Trop 112: 249-259.

Pate PG, Wolfson JS, McHugh CL, Pan SC, Swartz MN 1986. Novobiocin antagonism of amastigotes of Trypanosoma cruzi growing in cell-free medium. Antimicrob Agents Chemother 29: 426-431.

Plumbridge TW, Brown JR 1978. Studies on the mode of interaction of 4'-epi-adriamycin and 4-demethoxy-daunomycin with DNA. Biochem Pharmacol 27: 1881-1882.

Pommier Y, Leo E, Zhang H-L, Marchand C 2010. DNA topoisomerases and their poisoning by anticancer and antibacterial drugs. Chem Biol 17: 421-433.

Rothenberg ML 1997. Topoisomerase I inhibitors: review and update. Ann Oncol 8: 837-855.

Schwartz HS, Kanter PM 1981. DNA damage by anthracycline drugs in human leukaemia cells. Cancer Lett 13: 309-313.

Stevens JR, Teixeira MMG, Bingle LEH, Gibson WC 1999. The taxonomic position and evolutionary relationship of Trypanosoma rangeli. Int J Parasitol 29: 749-757.

Steverding D, Wang X 2009. Trypanocidal activity of the proteasome inhibitor and anti-cancer drug bortezomib. Parasit Vectors 2: 29.

Stewart L, Redinbo MR, Qui X, Hol WGL, Champoux JJ 1998. A model for the mechanism of human topoisomerase I. Science 279: 1534-1541.

Supino R, Necco A, Dasdia T, Casazza AM, di Marco A 1977. Relationship between effects on nucleic acid synthesis in cell cultures and cytotoxicity of 4-demethoxy derivatives of daunorubicin and adriamycin. Cancer Res 37: 4523-4528. 
Urbina JA, Docampo R 2003. Specific chemotherapy of Chagas disease: controversies and advances. Trends Parasitol 19: 495-501.

Westenberger SJ, Barnabé C, Campbell DA, Sturm NR 2005. Two hybridization events define the population structure of Trypanosoma cruzi. Genetics 171: 527-543.

WHO - World Health Organization 2010. Chagas disease (American trypanosomiasis). Fact Sheet 340. Available from: who.int $/ \mathrm{me-}$ diacentre/factsheets/fs340/en/.

Zingales B, Andrade SG, Briones MRS, Campbell DA, Chiari E, Fernandes O, Guhl F, Lages-Silva E, Macedo AM, Machado CR, Miles MA, Romanha AJ, Sturm NR, Tibayrenc M, Schijman AG
2009. A new consensus for Trypanosoma cruzi intraspecific nomenclature: second revision meeting recommends TcI to TcVI. Mem Inst Oswaldo Cruz 104: 1051-1054.

Zingales B, Miles MA, Campbell DA, Tibayrenc M, Macedo AM, Teixeira MMG, Schijman AG, Llewllyn MS, Lages-Silva E, Machado CR, Andrade SG, Sturm NR 2012. The revised Trypanosoma cru$z i$ subspecific nomenclature: rationale, epidemiological relevance and research applications. Infect Genet Evol 12: 240-253.

Zuma AA, Cavalcanti DP, Maia MCP, de Souza W, Motta MCM 2011. Effect of topoisomerase inhibitors and DNA-binding drugs on the cell proliferation and ultrastructure of Trypanosoma cruzi. Int $J$ Antimicrob Agents 37: 449-456. 